\title{
Release of the antimicrobial peptide LL-37 from DNA/F-actin bundles in cystic fibrosis sputum
}

\author{
R. Bucki, F.J. Byfield and P.A. Janmey
}

ABSTRACT: Cationic antibacterial peptides (ABPs) are secreted in the airways and function in the first line of defence against infectious agents. They attack multiple molecular targets to cooperatively penetrate and disrupt microbial surfaces and membrane barriers. Antibacterial properties of ABPs, including cathelicidin LL-37, are reduced in cystic fibrosis (CF) airways as a result of direct interaction with DNA and filamentous (F)-actin.

Microscopic evaluation of a mixed solution of DNA and F-actin, after the addition of rhodamineB-labelled LL-37 peptide, revealed the presence of a bundle structure similar to that present in CF sputum. Analysis of CF sputum after centrifugation showed that LL-37 was mostly bound to components of the pellet fraction containing DNA, F-actin and cell remnants. Factors that dissolve DNA/actin bundles and fluidise CF sputum, such as Dornase alfa (recombinant human DNase I), gelsolin, polyaspartate or their combinations, increased the amount of LL-37 peptide detected in the supernatant of CF sputum.

The presence of the bacterial endotoxin lipopolysaccharide (LPS) in CF sputum and the ability of LPS to inhibit the antibacterial activity of LL-37 suggests that inactivation of LL-37 function in CF sputum partially results from its interaction with LPS. LL-37-LPS interaction was prevented by an LPS-binding protein (LBP)-derived peptide known for its ability to neutralise LPS, whereas LBPW91A, a mutant peptide that lacks ability to bind LPS, had no effect.

A combination of factors that dissolve DNA/filamentous-actin aggregates together with lipopolysaccharide-binding agents may represent a potential treatment for the chronic infections that occur in cystic fibrosis airways.

KEYWORDS: Cystic fibrosis, gelsolin, lipopolysaccharide, LL-37 peptide, polyaspartate, recombinant human DNase I

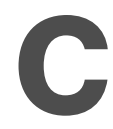
athelicidin LL-37, $\beta$-defensin, lactoferrin and lysozyme, which are expressed in the epithelium of the human lung and secreted into the airway surface fluid (ASF), are key elements in the responses of respiratory airways to the presence of bacteria [1, 2]. In cystic fibrosis (CF), ASF antibacterial activity has been found to be substantially reduced [3], partially as a result of high ionic strength [3-5] and direct interaction of antimicrobial peptides with DNA and filamentous (F)-actin [6, 7]. Defects in the biogenesis of airway secretions secondary to the CF transmembrane conductance regulator (CFTR) mutation may also contribute to the compromised antimicrobial activity of $\mathrm{CF}$ airways [4]. Despite the loss of antibacterial

For editorial comments see page 617 . function, $\mathrm{CF}$ epithelia still express bactericidal molecules, and the concentrations of known antibacterial factors in the ASF of CF subjects are not reduced when compared with ASF from normal epithelia [3, 8]. Overexpression of LL-37 after pulmonary gene transfection in mice was found to inhibit the bacterial load and inflammatory response following pulmonary Pseudomonas aeruginosa challenge, whereas systematic gene transfer was shown to protect against endotoxaemia, indicating interaction of LL-37/human cationic antimicrobial protein (hCAP)-18 with lipopolysaccharide (LPS) [9]. Recently, it was found that an increased concentration of LL-37 peptide in bronchoalveolar fluid correlates with higher severity of CF lung disease [8], but this increase is likely to result from an inflammatory reaction. Besides promoting chronic colonisation with $P$. aeruginosa, inactivation of antimicrobial

\section{AFFILIATIONS}

Dept of Physiology and the Institute for Medicine and Engineering, University of Pennsylvania, Philadelphia, PA, USA

\section{CORRESPONDENCE}

R. Bucki

Dept of Physiology and the Institute for Medicine and Engineering University of Pennsylvania 1010 Vagelos Research Laboratories 3340 Smith Walk

Philadelphia

PA

19104 USA

Fax: 12155737227

E-mail: buckirob@mail.med.upenn. edu

Received:

June 202006

Accepted after revision:

December 162006

SUPPORT STATEMENT

This study was supported by a

National Institute of Health grant

HL67286.

STATEMENT OF INTEREST

None declared. 
peptides in CF sputum may also influence specific inflammatory processes such as neutrophil activation and LPS-mediated cytokine production [8].

In addition to altered ionic and hydration states, sputum samples from CF patients contain large amounts of DNA [10] and F-actin [11] that contribute significantly to sputum viscosity. Both F-actin and DNA are anionic polyelectrolytes, with surface charges sufficiently high that a significant concentration of otherwise soluble cations is sequestered near the surface of these polymers. One result of polyvalent counterion condensation that overcomes the strong electrostatic repulsions between the filaments is the lateral association of such filaments into bundles. Antibacterial peptides, including cathelicidin LL-37, form heterogeneous bundles of DNA and F-actin [6] that dissolve after the addition of recombinant human (rh)DNase I, gelsolin or multivalent anions such as polymeric aspartate or glutamate $[7,12,13]$. Treatment of CF sputum with gelsolin or poly-aspartic acid (poly-ASP) lowers the elastic moduli of the samples and reduces the growth of bacteria, suggesting activation of endogenous antibacterial factors $[6,7]$. Loss of antibacterial peptide function represents one of several changes that underlie the molecular basis for chronic lung infection associated with CF [14]. The ability of $P$. aeruginosa to produce high levels of alginate, to grow as a biofilm in the CF lung and to express LPS molecules lacking O-antigen side chains with lipid A alterations that increase bacterial resistance to antibacterial peptides [15], also contribute to the complex phenomena of CF lung inflammation.

Anionic polymers of DNA and F-actin present in CF sputa, in addition to cationic antibacterial peptides, may also bind and mask neutrophil protease and chemokines such as interleukin (IL)-8. Reduction of CF sputum viscosity by rhDNase I or gelsolin in vitro has been demonstrated to increase the proportion of free IL- 8 and the IL-8-dependent neutrophil chemotactic activity of sputum supernatants [16]. However, in a previous study the increase in CF sputum protease activity after rhDNase I treatment was found to be a transient event, and the trend over 6 months was a reduction in both neutrophil elastase and IL-8 concentration [17].

Previous experiments have shown that different cationic antibacterial molecules present in CF sputum form bundled aggregates with DNA and F-actin [6], suggesting that depolymerisation of these bundles may release antibacterial agents trapped in their interior. The present study demonstrates, for the first time, that factors that depolymerise DNA and F-actin can liberate LL-37 from bundled structures in CF sputum and increase bactericidal activity. Additionally, it was found that the ability of LPS present in CF sputum [18] to inactivate the antibacterial function of the LL-37 peptide may explain why the function of antibacterial components present in CF sputum was only partially restored after treatment with rhDNase I, gelsolin or poly-ASP $[6,7]$. The finding that the ability of LPS to inactivate LL-37 activity may be prevented by LPS-binding protein (LBP)-derived peptides indicates that treatment with factors that dissolve DNA/F-actin aggregates in combination with LPS-binding agents may be more effective than either treatment alone to prevent or reverse the chronic infection in CF airways.

\section{MATERIALS AND METHODS Materials}

Tryptic soy broth and Pseudomonas isolation agar were acquired from DIFCO (Kansas City, MO, USA). Poly-aspartic acid, LPS (P. aeruginosa, serotype 10), and human placental DNA were purchased from Sigma (St Louis, MO, USA). Dornase alfa (rhDNase I; Pulmozyme ${ }_{\mathbb{R}}$ ) was obtained from Genentech Inc. (San Francisco, CA, USA), LL-37 and rhodamine-B-labelled LL-37 peptides were obtained from Bachem (King of Prussia, PA, USA). Human LBP-derived peptide, amino acids 86-99, which binds LPS in solution and inhibits LPS-induced cell responses as well as LPS interactions with protein [19, 20], was purchased from HyCult Biotechnology (Canton, MA, USA). LBPW91A mutant peptide in which tryptophan 91 is substituted by alanine, causing a lack of LPS binding [20], was obtained from GenScript (Piscataway, NJ, USA).

\section{Bundles of DNA and F-actin}

Globular actin was prepared from rabbit skeletal muscles as previously described [21] and polymerised to obtain F-actin. Heterologous bundles of these polymers were formed after mixing DNA $\left(2 \mathrm{mg} \cdot \mathrm{mL}^{-1}\right)$ with F-actin $\left(0.2 \mathrm{mg} \cdot \mathrm{mL}^{-1}\right)$ and rhodamine-B-labelled LL-37 peptide $(10 \mu \mathrm{M})$ after a 10 -min incubation at room temperature.

\section{Sputum samples}

CF sputum samples were collected by spontaneous expectoration from patients attending the University of Pennsylvania Health System Adult Cystic Fibrosis Center at the Presbyterian Hospital (PA, USA; IRB 803255). The samples were diluted in buffer containing $140 \mathrm{mM} \mathrm{NaCl}, 10 \mathrm{mM}$ Tris, $0.2 \mathrm{mM} \mathrm{CaCl}_{2}$ (pH 7.4) or PBS, vortexed and treated for $1 \mathrm{~h}$ with rhDNase I $\left(5-30 \mu \mathrm{g} \cdot \mathrm{mL}^{-1}\right)$, gelsolin $(0.5-2 \mu \mathrm{M})$, poly-Asp $(50 \mu \mathrm{M})$ or their combination. Samples were then centrifuged (10 $\mathrm{min}$; $15,500 \times g$ ) to pellet the remnant cells, bacteria and bundle structures. Samples used for experiments on patients receiving Pulmozyme ${ }_{\circledR}$ were obtained from independent collections.

\section{Optical microscopy}

Bundles of DNA and F-actin and samples of CF sputum were viewed using a Leica microscope (Leica, Bannockburn, IL, USA) using a $40 \times$ objective. Images were acquired using a Photometric Cool SNAP(HQ) camera (Roper Scientific, Trenton, NJ, USA). F-actin was labelled with rhodamine (tetramethylrhodamine-5-isothiocyanate) phalloidin (Sigma) and DNA was labelled with YOYO-1 (Molecular Probes, Boulder, CO, USA).

\section{Immunohistochemical studies}

Immunohistochemical studies were performed on formalinfixed, paraffin-embedded CF sputum sections and rat lung (data not shown; this condition was used as a positive control for antibody reactivity) using a rabbit anti-hCAP-18/LL-37 antibody that cross-reacts specifically with human and rat cathelicidin (H-075-06, used at 1:100 dilution; Phoenix Pharmaceuticals Inc., Belmont, CA, USA). Paraffin-embedded materials were sectioned at $5 \mu \mathrm{m}$ thickness and floated on distilled water at $45^{\circ} \mathrm{C}$. Sections were mounted on slides and placed in the oven at $57^{\circ} \mathrm{C}$ overnight. The sections were deparaffinised according to standard procedures and 
quenched with $0.9 \%$ hydrogen peroxide in methanol for $30 \mathrm{~min}$. The sections were incubated with primary antibody at $37^{\circ} \mathrm{C}$ for $60 \mathrm{~min}$, washed in a solution of $1 \%$ bovine serum albumin in PBS, and subjected to binding with secondary antibody (biotinylated goat anti-rabbit immunoglobulin G, 1:400 dilution). Amplification was performed with a Vectastain avidin-biotin peroxidase complex kit, and a horseradish peroxidase (HRP) detection system was used to colocalise peroxidase activity with a 3,3'-diaminobenzidine (DAB) substrate. The sections were counterstained with haematoxylin.

\section{Immunoblot analysis}

Samples of CF sputum were diluted 1:1 with $0.9 \% \mathrm{NaCl}$, mixed by vortexing with rhDNase I, poly-ASP, gelsolin or a combination of rhDNase I and gelsolin or rhDNase I and poly-ASP, and centrifuged. A dilution of whole CF sputum or supernatant was added to the gel sample buffer, boiled for $10 \mathrm{~min}$ and subjected to electrophoresis on a $10 \%$ sodium dodecyl sulphate-polyacrylamide gel electrophoresis (SDSPAGE) or $16.5 \%$ Tris-Tricine SDS-PAGE peptide analysis gel from Bio-Rad (Philadelphia, PA, USA) for LBP protein and LL-37 peptide analyses, respectively. After electrophoresis, proteins were transferred to nitrocellulose membranes (Immobilon-NC; Millipore, Billerica, MA, USA) that were blocked by incubation in $5 \%(\mathrm{w} / \mathrm{v})$ nonfat dry milk dissolved in TrisTween buffered saline (TTBS; $150 \mathrm{mM} \mathrm{NaCl}, 50 \mathrm{mM}$ Tris, $0.05 \%$ Tween 20, $\mathrm{pH} 7.4$ ). After transfer to the membrane, proteins were probed for $1 \mathrm{~h}$ with a polyclonal anti-LBP or monoclonal anti-LL-37/hCAP-18 antibody (clone 1-1C12, 1:250 dilution; HyCult Biotechnology, Canton, MA, USA) in TTBS. HRP-conjugated secondary antibodies were used at a 1:20,000 dilution in TTBS. Immunoblots were developed with Kodak BioMax MR film (Eastman Kodak Company, Rochester, NY, USA) using an HRP-targeted chemiluminescent substrate. The relative amount of LL-37 peptide and LBP in each lane was determined by gel densitometry, followed by image analysis with ImageQuant software (GMI Inc., Ramsey, MN, USA).

\section{LPS extraction and detection}

LPS extraction from CF sputum and P. aeruginosa culture (positive control) was performed using an LPS extraction kit from Intron Biotechnology (17144; Boca Scientific, Boca Raton, FL, USA) according to the manufacturer's instructions. Qualitative and quantitative analyses were made using a QCL-1000 Chromogenic end-point limulus amoebocyte lysate (LAL) assay (50-647U; Cambrex, Walkersville, MD, USA).

\section{Binding of LL-37 and LBP-derived peptide to LPS}

To evaluate whether the LBP-derived peptide can compete with LL-37 to bind LPS, a binding assay was performed based on previously described techniques [20]. Flat-bottomed multiwell polystyrene plates were coated with LPS $\left(2 \mathrm{nmol} \cdot \mathrm{well}^{-1}\right.$; LPS from $P$. aeruginosa) by incubation in $0.2 \%$ trichloroacetic acid at $37^{\circ} \mathrm{C}$ for $15 \mathrm{~h}$. Plates were then washed with PBS/0.1\% Tween 20, and rhodamine-B-labelled LL-37 peptide (2.55 nmolwell $\left.^{-1}\right)$ was added alone; with LPS ( $\left.2 \mathrm{nmol}\right)$; with LBP-derived peptide (2.5 nmol); or with LBPW91A peptide ( $2.5 \mathrm{nmol})$. After a 1-h incubation, plates were washed and the binding of rhodamine B-LL-37 peptide was detected fluorometrically (excitation and emission 544 and 590nm, respectively) using a multiple plate reader (Fluoroskan Ascent FL; Labsystems Inc., Franklin, MA, USA).

\section{Antimicrobial activity}

The bactericidal activity of LL-37 was measured as previously described [22]. Kanamycin-resistant $P$. aeruginosa were grown to mid-log phase at $37^{\circ} \mathrm{C}$, resuspended in PBS $(140 \mathrm{mM} \mathrm{NaCl}$, $\left.7.5 \mathrm{mM} \mathrm{Na} \mathrm{HPO}_{4} ; \mathrm{pH} 7.4\right)$ and brought to $10^{8}$ colony forming units (CFU) $\cdot \mathrm{mL}^{-1}$ (assuming that an optical density of 0.35 at $620 \mathrm{~nm}$ corresponds to $10^{8} \mathrm{CFU} \cdot \mathrm{mL}^{-1}$ ). The $P$. aeruginosa were then diluted 10 times in $100 \mu \mathrm{L}$ of PBS containing LL-37; LBPderived peptide; LL-37 and LPS; or the combination of LPS and LBP-derived peptide and LL-37. Similarly, tubes containing a dilution of CF sputum samples (1:20) were treated with rhDNase I or both rhDNase I and LBP-derived peptide $(5 \mu \mathrm{M})$. After a 1 -h incubation at $37^{\circ} \mathrm{C}$, the suspensions were placed on ice and diluted 10-1,000-fold in PBS and $10-\mu \mathrm{L}$ aliquots were spotted on Pseudomonas isolation agar plates for overnight culture at $37^{\circ} \mathrm{C}$. The number of colonies in the duplicate samples at each dilution was counted the following morning, and the number of CFU. $\mathrm{mL}^{-1}$ in each sample was determined from the dilution factor.

\section{RESULTS \\ Visualisation of DNA and F-actin in CF sputum}

Individual or mixed bundles of DNA and F-actin form when these anionic polyelectrolytes are mixed with cationic antimicrobial peptides [6] or histones [7]. In the present study, bundle formation was observed after mixing DNA and F-actin with rhodamine B-labelled LL-37 peptide (fig. 1). The addition of fluorescent phalloidin or YOYO-1 to control samples of F-actin and DNA alone results in uniform, low-intensity labelling, without any detectable structures when phase contrast observation was performed (fig. 1a). When rhodamine-B-labelled LL-37 was added to F-actin and DNA, bundles formed that were positive for fluorescence of both the filaments and LL-37, indicating an ability of the LL-37 peptide to induce the formation of these structures (fig. 1b). As shown in figure 1c, similar bundles containing DNA and F-actin are found in the complex environment of whole CF sputum.

\section{Immunohistochemical probing of CF sputum sections with anti-LL-37/hCAP-18 antibody}

Microscopic images of CF sputum after immunohistochemical evaluation with anti-LL-37/hCAP-18 antibody are shown in figure $1 \mathrm{~d}$. The presence of DAB-positive, elongated structures (arrows) positively labelled with haematoxylin, which labels DNA (fig 1d, upper panel), indicates the presence of the LL-37 peptide and/or its parent protein in bundles from CF sputum. The high intensity of the DAB signal suggests that LL-37 and hCAP-18 are present in CF sputum at high concentrations.

\section{Immunoblotting analysis of LL-37 peptide in CF sputum}

Figure 2a illustrates the results from the immunoblotting analysis of six different CF sputum samples with an anti-LL$37 /$ hCAP-18 antibody. The two upper rows compare representative immunoblots of samples obtained from CF patients who were (S1) or were not (S2) receiving Pulmozyme treatment before CF-sputum collection. The analysis revealed that LL-37 peptide is mostly bound to the contents of CF pellets (lane 1 representing the total amount of LL-37 peptide in the 


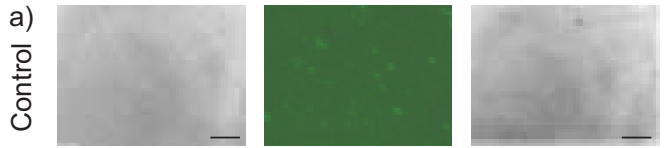

F-actin + phalloidin
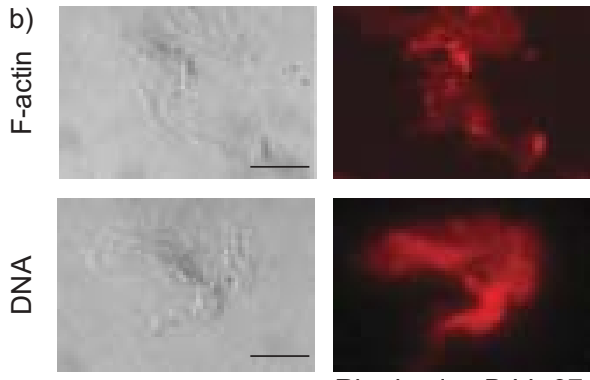

Rhodamine B-LL-37
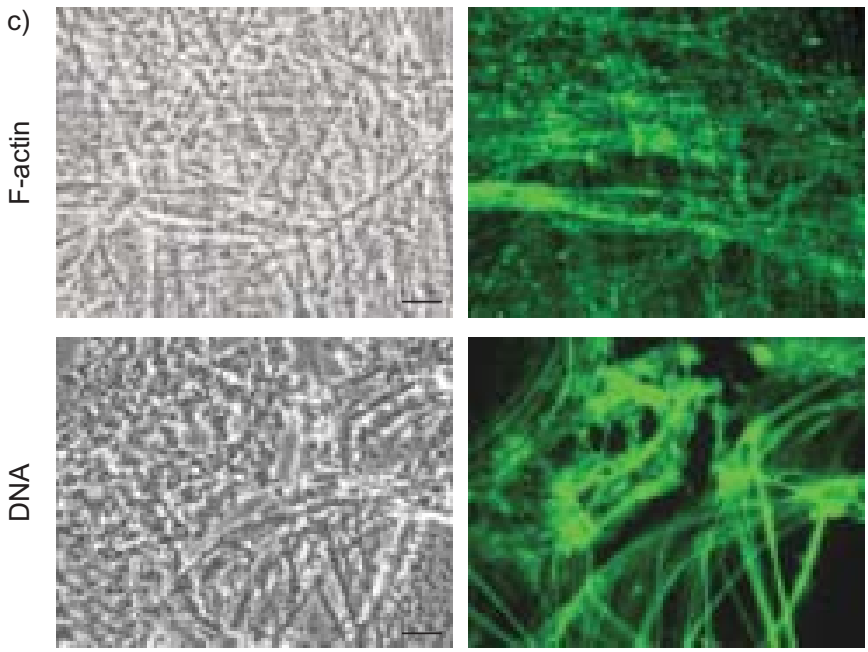
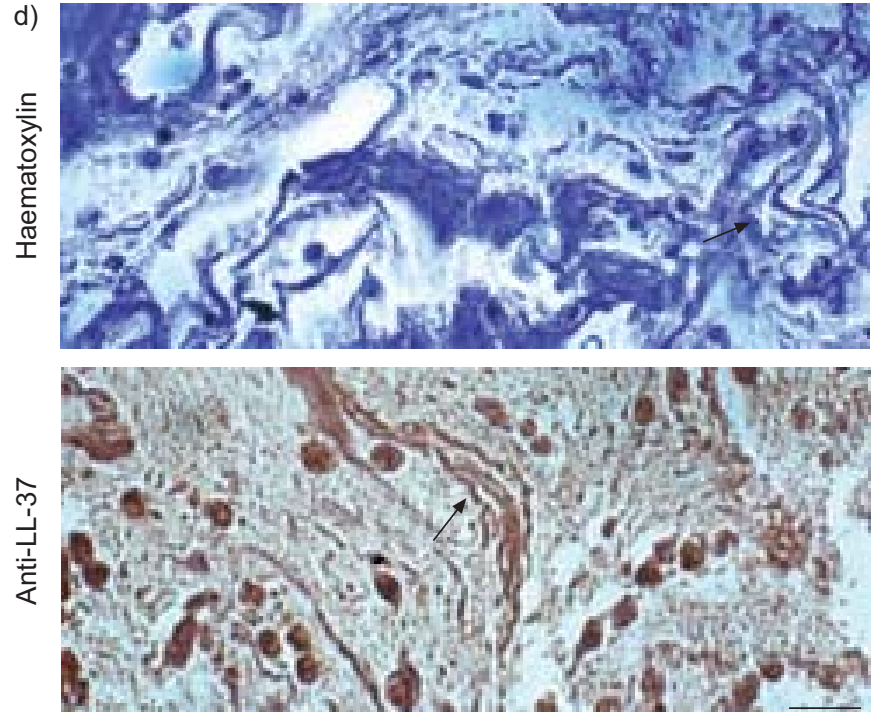

FIGURE 1. a) Presence of DNA and filamentous (F)-actin in mixed bundles and $b$ ) following the addition of rhodamine B-labelled LL37 peptide. c) F-actin and DNA bundles in cystic fibrosis (CF) sputum samples. F-actin and DNA were visualised by Alexa-Fluor phalloidin and YOYO-1 labelling, respectively. The morphology of corresponding samples is shown by phase contrast microscopy (black and white images) and the data shown are representative of three experiments; scale bars $=200 \mu \mathrm{m}$. d) Immunohistochemical staining of CF sputum with anti-LL-37/human cationic antimicrobial protein-18 antibody representative of two experiments. Arrows indicate the presence of elongated strands. Scale bar $=20 \mu \mathrm{m}$. whole volume of CF sputum, versus lane 2 representing the amount of LL-37 peptide in the supernatant of a corresponding volume). Densitometry analysis of the blots of six patients' sputum samples showed that the LL-37 peptide present in the CF sputum supernatant fraction accounts for $5.4-35 \%$ of its total concentration. Besides detectable heterogeneity among the analysed samples regarding LL-37 concentration, it was found that treatment of CF sputum with rhDNase I (lane 3), gelsolin (lane 4), poly-ASP (lane 5) or a combination of rhDNase I with gelsolin (lane 6) or with poly-ASP (lane 7) increases the amount of LL-37 in the supernatant fraction to varying extents $(9-73 \%)$. In all samples, the combination of rhDNase I with gelsolin or poly-ASP was found to be more effective in increasing the LL-37 peptide concentration in the supernatant fraction than any individual treatment. This observation is in agreement with the previously reported ability of gelsolin [13] and poly-ASP [7] to increase rhDNase I activity, in addition to their effects on the rheological properties of CF sputum. LL-37 release was specific, as the concentration of soluble LBP, which does not bind actin or DNA, did not follow the pattern of changes in LL-37 concentration (fig. $2 \mathrm{~b}$ ). The release of antibacterial peptides from DNA/F-actin bundles was found to have a significant but incomplete effect on the bacterial load of CF sputum [6] and motivated a search for other CF components that may interfere with bactericidal activity.

\section{Bacterial endotoxin and LBP protein are present in CF sputum}

Samples of CF sputum were obtained from five patients that tested positive for chronic infection with P. aeruginosa (four of whom were currently receiving Pulmozyme ${ }_{\mathbb{R}}$ ) and were analysed for the presence of LPS and LBP. Both the total volume and supernatant (obtained after centrifugation) of $\mathrm{CF}$ sputum (1:10 dilution in endotoxin-free water) were subjected to LPS extraction and quantitative analysis with an LAL assay or electrophoresis followed by immunoblotting analysis with an anti-LBP antibody. The present study revealed that the average concentration of LPS in the total volume of CF sputum was $40.9 \pm 19.1$ experimental units $(\mathrm{EU}) \cdot \mathrm{mL}^{-1}(\sim 0.02 \mu \mathrm{M})$ and $\sim 50 \%$ of this amount was identified in the sputum supernatant fraction $\left(19.0 \pm 4.9 \mathrm{EU} \cdot \mathrm{mL}^{-1}\right)$. Due to the unknown and possibly low efficiency of LPS extraction from CF sputum, and the unknown dilution of CF sputum caused by expectoration, these values must be interpreted qualitatively as documenting relative amounts of LPS, rather than as absolute concentrations, which may be significantly higher.

A centrifugation force applied to the CF sputum supernatant fraction $(10 \mathrm{~min}$ at $15,000 \times g)$ normally causes sedimentation of intact bacteria. Therefore, LPS in the supernatant represents an LPS fraction already released from the bacterial wall. Figure $2 b$ shows that, in addition to LL-37, acute-phase 
a)
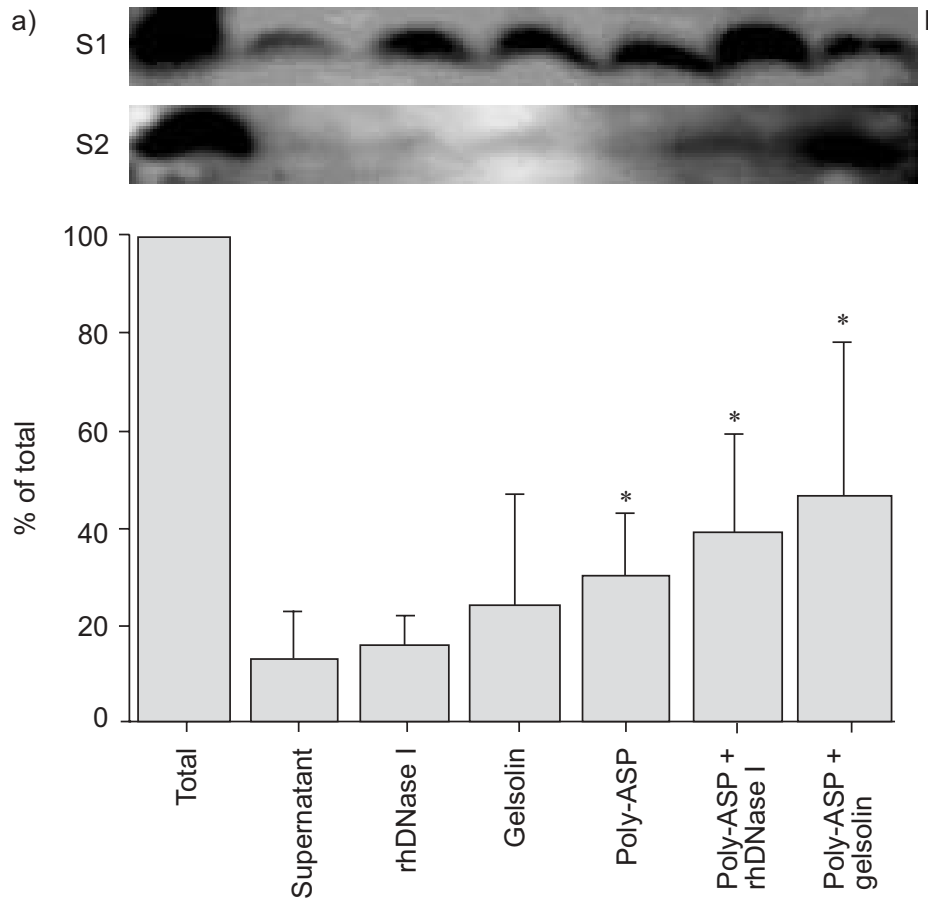

Samples b) $\mathrm{s} 1$
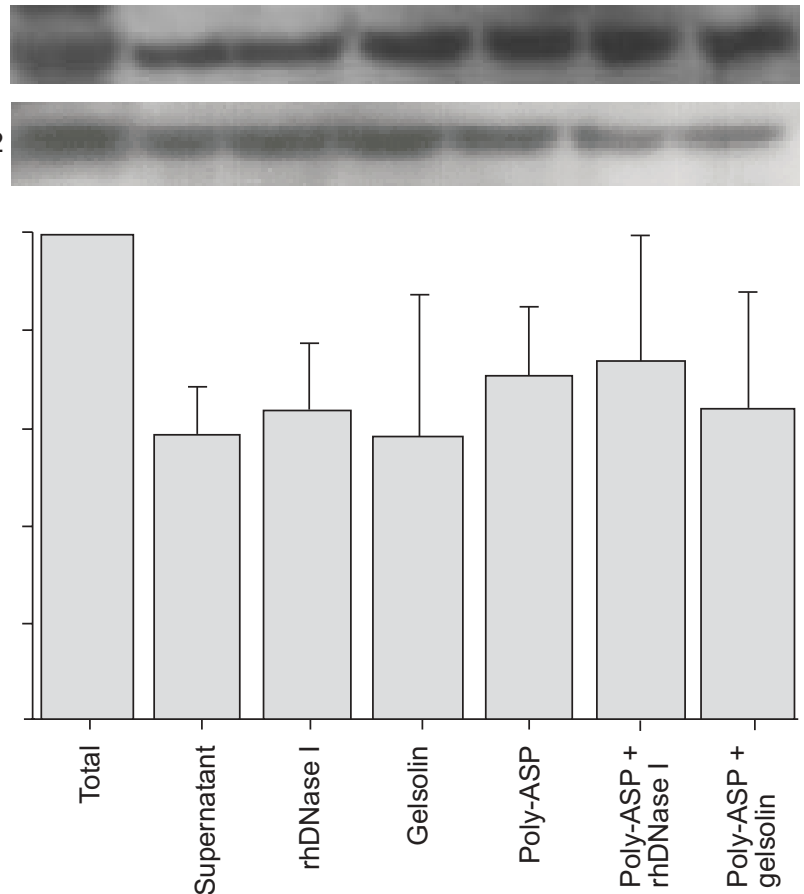

Samples

FIGURE 2. Presence of a) LL-37 and b) lipopolysaccharide binding protein (LBP) in cystic fibrosis (CF) sputum detected using immunoblotting analysis with monoclonal antibodies to human LL-37/human cationic antimicrobial protein-18 and human LBP protein, respectively. The upper row represents analysis of the individual samples in patients with (S1) or without (S2) recombinant human DNase I treatment prior to sample collection. Lanes 2-7 represent the amount of LL-37 or LBP detected after the addition of: rhDNase I (30 $\left.\mu \mathrm{g} \cdot \mathrm{mL}^{-1}\right)$; gelsolin $(2 \mu \mathrm{M})$; poly-aspartic acid (poly-ASP; $\left.50 \mu \mathrm{M}\right)$; rhDNase I $\left(30 \mu \mathrm{g}^{\left.-\mathrm{mL}^{-1}\right)}\right.$ and gelsolin $(2 \mu \mathrm{M})$; or rhDNase I $\left(30 \mu \mathrm{g} \cdot \mathrm{ml}^{-1}\right)$ and polyASP $(50 \mu \mathrm{M})$, respectively. Quantitative immunoblot analysis represents the concentration of LL-37 or LBP in samples as a percentage of the total concentration in the whole volume of individual CF sputa. Data represents the mean of six and five different samples for LL-37 and LBP, respectively. Differences in this experiment were evaluated with unpaired t-tests, with $p<0.05$ taken as the level of significance. ${ }^{*}$ : $p<0.05$ versus the respective value in supernatant.

reactant LBP that also binds bacterial LPS is present in CF sputum and is mostly found in the supernatant fraction. This finding suggests that in the supernatant of CF sputum, LPS may combine with LL-37, antibodies to LPS [23] and LPB protein, one of the critical molecules regulating the airway response to LPS [24, 25]. Even if the average, free concentration of LPS in CF sputum is low, its distribution in the whole volume may differ, rising specifically in regions of bacterial growth that are the principle targets for antibacterial peptides. The presence of LBP in CF sputum suggests that LPS in CF airways may be presented to toll-like receptors [26], stimulating the local production of inflammatory cytokines, especially by type II pneumocytes [27].

\section{Inactivation of LL-37 by LPS is reversed by LBP}

Evaluation of LL-37 peptide interaction with LPS-coated plates in the presence of LPS, LBP and LBPW91A revealed that binding of rhodamine-B-labelled LL-37 (2.55 nmol) to LPS ( $2 \mathrm{nmol}$ )-coated plates decreased in the presence of LPS ( $2 \mathrm{nmol}$ ) and LPB peptide ( $2.5 \mathrm{nmol})$ by $52 \pm 8 \%$ and $39 \pm 12 \%$, respectively, whereas a control LBPW91A peptide $(2.5 \mathrm{nmol})$ had no effect on LL-37 binding to the LPS-coated surface.

One consequence of the interaction of LPS with LL-37 is the inhibition of its antibacterial activity. LPS alone had no effect on $P$. aeruginosa bacteria when evaluated using a bacteria killing assay (fig. 3). LL-37 at a concentration of $\sim 1 \mu \mathrm{M}$ kills almost all bacteria (fig. 3a), but the addition of LPS $(0.5-5 \mu \mathrm{M})$ restored bacterial growth to the original level. These data confirm the functional interaction of LL-37 with LPS. LBPderived peptide prevented LPS from inhibiting the antibacterial function of LL-37. When the LL-37 peptide $(1 \mu \mathrm{M})$ was treated with LPS $(0.5 \mu \mathrm{M})$ in the presence of LBP-derived peptide $(1 \mu \mathrm{M})$, its antibacterial activity was restored (fig. $3 b$ ). At the concentration used in this assay, LBP-derived peptide alone had no significant effect on $P$. aeruginosa growth. The specificity of the LBP-derived peptide's ability to prevent inactivation of LL-37 by LPS was confirmed by the lack of effect of an LPBW91A mutant peptide that lacks LPS binding.

\section{Bacterial load of CF sputa after treatment with a combination of Pulmozyme ${ }_{\mathbb{R}}$ and LBP}

LBP-derived peptide alone appeared to have no significant effect on CF sputum bacterial outgrowth, but CFU from four out of six analysed samples was reduced after rhDNase I treatment (fig. 4). Combination of rhDNase I with $5 \mu \mathrm{M} \mathrm{LBP}$ had a more distinct effect (10-35\% decrease of CFU in sputum samples). This result suggests that antibacterial peptides released from CF sputum bundles are partially inhibited by LPS, and the effect of LPS can be prevented by LPSneutralising molecules such as LBP-derived peptide. 

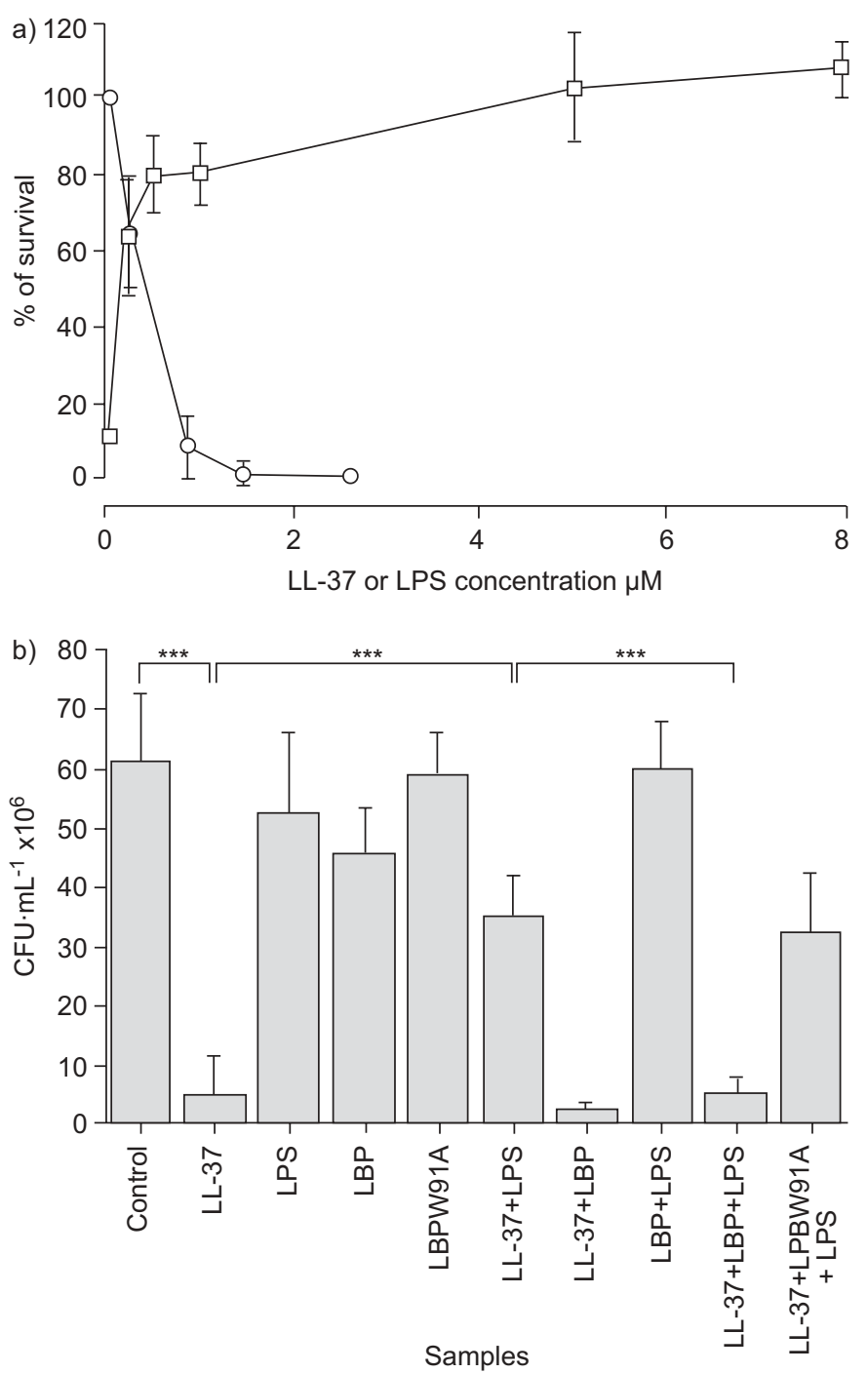

FIGURE 3. a) Viability of Pseudomonas aeruginosa after a 1 -h incubation with varying concentrations of LL-37 $(O)$ or a combination of LL-37 $(1 \mu \mathrm{M})$ and lipopolysaccharide (LPS; $0.1-5 \mu \mathrm{M} ; \square$ ). The effect of peptides was calculated by taking the number of colony-forming units (CFUs) in the no treatment sample (growth control) as $100 \%$. b) The ability of LPS-binding protein (LBP)-derived peptide to prevent LPS-mediated inhibition of LL-37 bactericidal activity. Viability of $P$. aeruginosa was evaluated in the presence of LL-37 $(1 \mu \mathrm{M}), \operatorname{LBP}(1 \mu \mathrm{M})$ and LBPW91A $(1 \mu \mathrm{M})$ or their combination in the presence of LPS from $P$. aeruginosa $(0.5 \mu \mathrm{M})$. Data represents the mean of four experiments with differences evaluated by unpaired t-test; $p<0.05$ was taken as the level of significance. ${ }^{\star * *}$ : $p<0.001$ versus the respective value.

\section{DISCUSSION}

Airway inflammation is recognised as a major factor in the pathogenesis of CF lung disease. While there appears to be no immune deficiency in patients with $\mathrm{CF}$, the defect in CFTR increases the susceptibility of the lungs to endobronchial infections by bacteria [28-30]. One of the mechanisms proposed to explain this susceptibility to pulmonary infection points to reduced antibacterial properties in the layer of fluid that lines the airways $[1,3]$. Previous attempts to increase the bactericidal activity of the CF ASF have focused on: airway epithelial cell transfection with hCAP-18 to increase local production of LL-37 [9]; engineered exogenous antibacterial sequences that display high activity against $P$. aeruginosa [31]; peptide mimetic molecules [32]; or salt-insensitive antimicrobial peptides [33]. Limiting the inflammatory response in the CF lung may also be effective in slowing the course of the disease. The mechanisms by which the inflammatory response occurs in the CF lung have also been considered as new therapeutic targets [34]. The lack of antibacterial activity of $\mathrm{CF}$ ASF, coexisting with a normal or higher [8] concentration of antibacterial peptides, indicates local inactivation of antimicrobial factors in CF sputum. Both DNA [10] and F-actin [11] present in $\mathrm{CF}$ sputum are anionic polyelectrolytes with negative surface charges sufficiently high that positively charged antibacterial peptides, which are otherwise soluble, may be sequestered at the surface of the polymers, leading to their aggregation into bundles. Interactions of DNA and Factin with antibacterial peptides contribute to the altered viscoelastic properties of sputum and result in inactivation of various antimicrobial factors [6, 7]. As therapeutic approaches to treat $\mathrm{CF}$ lung infection, strategies aiming to recover the endogenous antibacterial function of peptides present in CF sputum may have advantages over the expression or introduction of exogenous antimicrobial factors. Modulation of the CF environment to overcome its ability to inhibit bactericidal activity is also necessary for the effective use of exogenous antibacterial peptides as well as for the optimal function of antibacterial factors over-expressed after gene therapy.

Based on previous observations that agents able to dissolve $\mathrm{CF}$ sputa bundles had limited effect on CF bacterial load [7], the present study attempted to identify other factors that inactivate bactericidal activity in CF airways and the mechanisms through which they act. It was found that factors that depolymerise bundles of CF DNA and F-actin simultaneously release cationic antibacterial molecules. This was shown by an increase in LL-37 peptide concentration in the supernatant fraction of CF sputum (fig. 2). The ability of LPS released from the bacterial wall to inactivate the antibacterial function of LL37 [35] contributes to the loss of bactericidal activity of the CF ASF. This inactivation of LL-37 can be prevented by an LBPderived peptide, known for its ability to modulate LPS cellular effects. This finding suggests that a combination of factors that dissolve DNA/F-actin aggregates with LPS binding agents may have potential for the treatment of chronic infection in $\mathrm{CF}$ airways.

The inhibition of the LL-37 peptide by lipopolysaccharide, and the prevention of this effect by the lipopolysaccharide-binding protein, is likely to be only one aspect of the modulatory effect of the lipopolysaccharide-binding protein on LL-37-lipopolysaccharide interactions. Human cationic antimicrobial protein18/LL-37-lipopolysaccharide complexes may also activate cell receptors, as has been shown for the soluble form of the lipopolysaccharide CD14 receptor that can either inhibit or enhance cellular response to lipopolysaccharide [36]. The lipopolysaccharide-binding protein can also either enhance or inhibit the cellular response to lipopolysaccharide, depending in part on the presence of other lipopolysaccharide-binding molecules to which the lipopolysaccharide-binding protein may facilitate transfer [37]. The finding that LL-37 may compete with the lipopolysaccharide-binding protein for lipopolysaccharide binding suggests that, at inflammatory 

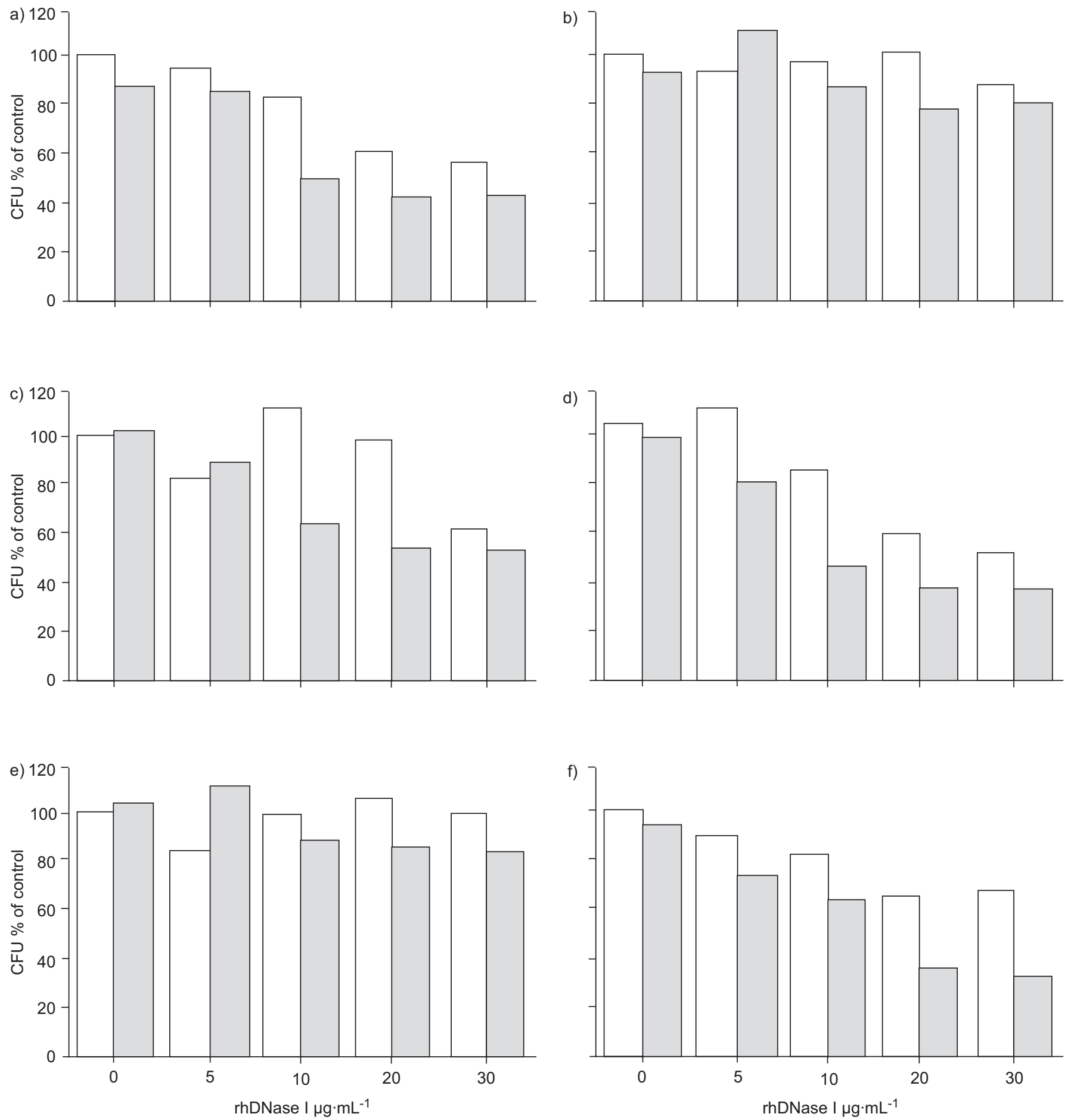

FIGURE 4. Bacterial load of cystic fibrosis sputa in six different samples, a)-f), after treatment with recombinant human (rh)-DNase I alone ( $\square$ ), or in combination with $5 \mu \mathrm{M}$ lipopolysaccharide-binding protein ( $\square$ ). Data were normalised by taking the number of colony forming units (CFUs) in the untreated samples (growth control) as $100 \%$.

sites in the respiratory system [38] and elsewhere, the delivery of lipopolysaccharide to cellular receptors, lipoprotein, or other targets mediated by the lipopolysaccharide-binding protein, would be perturbed when human cationic antimicrobial protein/LL-37 levels change. The dual role of the lipopolysaccharide-binding protein and CD14 in innate immunity has been recently established [39], and the possibility that human cationic antimicrobial protein/LL-37 may also participate in the interactions of these proteins with lipopolysaccharide [40] deserves future investigation.

\section{ACKNOWLEDGEMENTS}

The authors wish to thank J. Nichol (University of Pennsylvania, PA, USA) for assistance with immunohistochemical staining 
of CF sputum samples with the anti-LL-37/hCAP-18 antibody. The authors also gratefully acknowledge the assistance of $\mathrm{M}$. Ferrin (Adult Cystic Fibrosis Center of the University of Pennsylvania, PA, USA) and patients of the Adult Cystic Fibrosis Center of the University of Pennsylvania, for providing sputum samples.

\section{REFERENCES}

1 Travis SM, Conway BA, Zabner J, et al. Activity of abundant antimicrobials of the human airway. Am J Respir Cell Mol Biol 1999; 20: 872-879.

2 Fahy RJ, Wewers MD. Pulmonary defense and the human cathelicidin hCAP-18/LL-37. Immunol Res 2005; 31: 75-90.

3 Smith JJ, Travis SM, Greenberg EP, Welsh MJ. Cystic fibrosis airway epithelia fail to kill bacteria because of abnormal airway surface fluid. Cell 1996; 85: 229-236.

4 Bals R, Weiner DJ, Meegalla RL, Accurso F, Wilson JM. Salt-independent abnormality of antimicrobial activity in cystic fibrosis airway surface fluid. Am J Respir Cell Mol Biol 2001; 25: 21-25.

5 Goldman MJ, Anderson GM, Stolzenberg ED, Kari UP, Zasloff M, Wilson JM. Human $\beta$-defensin- 1 is a saltsensitive antibiotic in lung that is inactivated in cystic fibrosis. Cell 1997; 88: 553-560.

6 Weiner DJ, Bucki R, Janmey PA. The antimicrobial activity of the cathelicidin LL-37 is inhibited by F-actin bundles and restored by gelsolin. Am J Respir Cell Mol Biol 2003; 28: 738-745.

7 Tang JX, Wen Q, Bennett A, et al. Anionic poly(amino acid)s dissolve F-actin and DNA bundles, enhance DNase activity, and reduce the viscosity of cystic fibrosis sputum. Am J Physiol Lung Cell Mol Physiol 2005; 289: L599-L605.

8 Chen CI, Schaller-Bals S, Paul KP, Wahn U, Bals R. $\beta$-defensins and LL-37 in bronchoalveolar lavage fluid of patients with cystic fibrosis. J Cyst Fibros 2004; 3: 45-50.

9 Bals R, Weiner DJ, Moscioni AD, Meegalla RL, Wilson JM. Augmentation of innate host defense by expression of a cathelicidin antimicrobial peptide. Infect Immun 1999; 67: 6084-6089.

10 Brandt T, Breitenstein S, von der Hardt H, Tummler B. DNA concentration and length in sputum of patients with cystic fibrosis during inhalation with recombinant human DNase. Thorax 1995; 50: 880-882.

11 Vasconcellos CA, Allen PG, Wohl ME, Drazen JM, Janmey PA, Stossel TP. Reduction in viscosity of cystic fibrosis sputum in vitro by gelsolin. Science 1994;263: 969-971.

12 Ulmer JS, Herzka A, Toy KJ, et al. Engineering actinresistant human DNase I for treatment of cystic fibrosis. Proc Natl Acad Sci USA 1996; 93: 8225-8229.

13 Davoodian K, Ritchings BW, Ramphal R, Bubb MR. Gelsolin activates DNase I in vitro and cystic fibrosis sputum. Biochemistry 1997; 36: 9637-9641.

14 Pier GB. Peptides, Pseudomonas aeruginosa, polysaccharides and lipopolysaccharides-players in the predicament of cystic fibrosis patients. Trends Microbiol 2000; 8: 247-250.

15 Ernst RK, Yi EC, Guo L, et al. Specific lipopolysaccharide found in cystic fibrosis airway Pseudomonas aeruginosa. Science 1999; 286: 1561-1565.

16 Perks B, Shute JK. DNA and actin bind and inhibit interleukin-8 function in cystic fibrosis sputa: in vitro effects of mucolytics. Am J Respir Crit Care Med 2000; 162: 1767-1772.
17 Shah PL, Scott SF, Knight RA, Hodson ME. The effects of recombinant human DNase on neutrophil elastase activity and interleukin-8 levels in the sputum of patients with cystic fibrosis. Eur Respir J 1996; 9: 531-534.

18 Kronborg G. Lipopolysaccharide (LPS), LPS-immune complexes and cytokines as inducers of pulmonary inflammation in patients with cystic fibrosis and chronic Pseudomonas aeruginosa lung infection. APMIS Suppl 1995; 50: 1-30.

19 Bucki R, Pastore JJ. Bacterial endotoxin as inhibitor of the enzymatic activity of human thrombin. Eur J Haematol 2006; 76: 510-515.

20 Arana Mde J, Vallespi MG, Chinea G, et al. Inhibition of LPS-responses by synthetic peptides derived from LBP associates with the ability of the peptides to block LBP-LPS interaction. J Endotoxin Res 2003; 9: 281-291.

21 Tang JX, Janmey PA. The polyelectrolyte nature of F-actin and the mechanism of actin bundle formation. J Biol Chem 1996; 271: 8556-8563.

22 Silvestro L, Weiser JN, Axelsen PH. Antibacterial and antimembrane activities of cecropin A in Escherichia coli. Antimicrob Agents Chemother 2000; 44: 602-607.

23 Lagace J, Mercier J, Frechette M, et al. Circulating immune complexes, antibodies to Pseudomonas aeruginosa, and pulmonary status in cystic fibrosis. J Clin Lab Immunol 1989; 30: 7-11.

24 Brass DM, Savov JD, Whitehead GS, Maxwell AB, Schwartz DA. LPS binding protein is important in the airway response to inhaled endotoxin. J Allergy Clin Immunol 1989; 114: 586-592.

25 Kato A, Ogasawara T, Homma T, Saito H, Matsumoto K. Lipopolysaccharide-binding protein critically regulates lipopolysaccharide-induced IFN- $\beta$ signaling pathway in human monocytes. J Immunol 2004; 172: 6185-6194.

26 Muir A, Soong G, Sokol S, et al. Toll-like receptors in normal and cystic fibrosis airway epithelial cells. Am J Respir Cell Mol Biol 2004; 30: 777-783.

27 Schulz C, Farkas L, Wolf K, Kratzel K, Eissner G, Pfeifer M. Differences in LPS-induced activation of bronchial epithelial cells (BEAS-2B) and type II-like pneumocytes (A-549). Scand J Immunol 2002; 56: 294-302.

28 Heeckeren A, Walenga R, Konstan MW, Bonfield T, Davis PB, Ferkol T. Excessive inflammatory response of cystic fibrosis mice to bronchopulmonary infection with Pseudomonas aeruginosa. J Clin Invest 1997; 100: 2810-2815.

29 Tirouvanziam R, de Bentzmann S, Hubeau C, et al. Inflammation and infection in naive human cystic fibrosis airway grafts. Am J Respir Cell Mol Biol 2000; 23: 121-127.

30 Gibson RL, Burns JL, Ramsey BW. Pathophysiology and management of pulmonary infections in cystic fibrosis. Am J Respir Crit Care Med 2003; 168: 918-951.

31 Deslouches B, Islam K, Craigo JK, Paranjape SM, Montelaro $\mathrm{RC}$, Mietzner TA. Activity of the de novo engineered antimicrobial peptide WLBU2 against Pseudomonas aeruginosa in human serum and whole blood: implications for systemic applications. Antimicrob Agents Chemother 2005; 49: 3208-3216.

32 Savage PB, Li C, Taotafa U, Ding B, Guan Q. Antibacterial properties of cationic steroid antibiotics. FEMS Microbiol Lett 2002; 217: 1-7. 
33 Beringer PM. New approaches to optimizing antimicrobial therapy in patients with cystic fibrosis. Curr Opin Pulm Med 1999; 5: 371-377.

34 Konstan MW, Davis PB. Pharmacological approaches for the discovery and development of new anti-inflammatory agents for the treatment of cystic fibrosis. Adv Drug Deliv Rev 2002; 54: 1409-1423.

35 Bucki R, Janmey PA. Interaction of the gelsolin-derived antibacterial PBP 10 peptide with lipid bilayers and cell membranes. Antimicrob Agents Chemother 2006; 50: 2932-2940.

36 Haziot A, Rong GW, Bazil V, Silver J, Goyert SM. Recombinant soluble CD14 inhibits LPS-induced tumor necrosis factor- $\alpha$ production by cells in whole blood. J Immunol 1994; 152: 5868-5876.
37 Thompson PA, Tobias PS, Viriyakosol S, Kirkland TN, Kitchens RL. Lipopolysaccharide (LPS)-binding protein inhibits responses to cell-bound LPS. J Biol Chem 2003; 278: 28367-28371.

38 Knapp S, Florquin S, Golenbock DT, van der Poll T. Pulmonary lipopolysaccharide (LPS)-binding protein inhibits the LPS-induced lung inflammation in vivo. J Immunol 2006; 176: 3189-3195.

39 Heumann D, Lauener R, Ryffel B. The dual role of LBP and CD14 in response to Gram-negative bacteria or Gramnegative compounds. J Endotoxin Res 2003; 9: 381-384.

40 Scott MG, Vreugdenhil AC, Buurman WA, Hancock RE, Gold MR. Cutting edge: cationic antimicrobial peptides block the binding of lipopolysaccharide (LPS) to LPS binding protein. J Immunol 2000; 164: 549-553. 